\title{
Internet Via Mobile Devices Among Graduate Students of the University of Ghana
}

\author{
* David Doe Ayornoo \\ MA. Ada College of Education. Ada-Eastern.Ghana West Africa \\ Frederick Mensah Bonsu \\ MPhil/Med. Wesley College of Education, \\ Kumasi- Ashanti. Ghana West-Africa
}

\begin{abstract}
This study focused on the use of the Internet via mobile devices among graduate students of the University of Ghana. The survey methodology was used to analyze the perceived use, attitude of graduate students of the University of Ghana (UG) towards the use of the Internet via mobile devices. The respondents numbering 244 answered questions on attitude, perceived ease of use, actual use and challenges of the Internet via mobile devices among graduate students of UG. Responses were analyzed to ascertain the use of the Internet via mobile devices among graduate students in the University. The study revealed that graduate students of UG used mobile phones in accessing the Internet for their information needs due to its portability, easy use, faster and convenience. Additionally the students used MTN as their core telecom network service to access the Internet. Besides, mobile devices were used for academic purposes especially for research work. The benefits obtained by the students in accessing the Internet via mobile devices included broadening of knowledge, convenience of search and wider access to information. Major limitations however were small screen size, low memory capacity, slow transmission speed and lack of skill to operate the mobile device. In conclusion, the Technology Acceptance Model via Wireless Internet should be used for all graduate students' programmes, because Internet via mobile devices has a unique role in UG. The study recommended a partnership between Internet Service Providers (ISPs) and Technology Manufacturers to tailor made mobile devices that support Internet access and also meet the desired needs of students whilst ISPs and UG management respectively improve on Internet services and integrate mobile devices to teaching, learning and research activities.
\end{abstract}

Keywords: Technology Acceptance Model (TAM), Ease of Use (EOU) and Information Communication Technology (ICT)

DOI: $10.7176 / \mathrm{JEP} / 11-6-14$

Publication date: February $29^{\text {th }} 2020$

\section{Background to the study}

Globally, mobile devices are being used to access the Internet for information. It is, however, a small section of the populace who access the Internet through these devices. Several factors account for the low use of the Internet, one of which is the fact that the elderly in society are of the view that technology is for the younger generation and this explains why older workers in organizations are reluctant to use this technology, compared to workers who fall within the youth bracket. Wireless communications and services are aided by the coming together of two technologies- the Internet and wireless technology like mobile phones and Personal Digital Assistants. The increase in growth of Wireless Internet via Mobile Devices (WIMD) is creating unparalleled opportunities for electronic (e)-commerce. Consumers and businesses are enabled to build connectivity by going beyond the range of time and place, increasing accessibility and enlarging their social and business networks. The increase in growth shall ensure their ubiquity, convenience, localization and personalization for users of communications and service activities (Lu et al., 2003).

Bruner and Kumar (2003) assert that the success of mobile commerce depends on the willingness of consumers to adapt a brand new technology and engage in operations with the use of systems and devices which are at variance with what they have used previously. The Technology Acceptance Model (TAM) is used to predict employees' behaviours and attitude when introduced to new technologies in workplaces. The use of TAM gives insight regarding the factors that affect consumers' acceptance of technology. TAM asserts that usefulness and Ease of Use (EOU) influence the intention of an individual in using a system. The main idea behind TAM is that a person's behavioural intention to use a system is influenced by two main factors: its EOU and its usefulness. Usefulness is the extent to which a person believes a system can perform a task. However EOU is the level at which an individual thinks that using a system will be free of mental effort.

Asif and Krogstie (2011) posit that mobile learning devices have become much more diverse groups of wearable and portable technologies. Cell phones and other mobile devices are shifting from being a luxury to a necessary commodity and thus ordinary consumers are increasingly adopting mobile devices. Internet connection has become accessible and present everywhere simultaneously through the use of mobile devices. Graduate 
students stand to benefit through mobile Internet if they accept the model as an alternative to desktop Internet access. Mobile information systems were expanding fast with regard to when and where to execute learning for various settlements. Communication between teachers and students was changing very fast through mobile computing, which could also be used to effectively develop instructional quality. Campus information system for students is described as 'An integrated group of information resources, accessible by computer through the campus institutional external and internal web environment, that a university places at the disposal of its users to enable them to consult it and/or provide a selection of significant and relevant data, in the wide context of their university life in its academic, administrative and social senses, in order to improve student's knowledge base'. This idea holds true for new students who are unfamiliar with present day routines and practices. New students may also find it difficult to locate their bearings on campus. Thus, it is important to have key information accessible to students on university campuses, especially among graduate students.

School of Research and Graduate Studies (2010) posits that, the University of Ghana (UG) was established in 1948 by the name University College of the Gold Coast on the recommendation of Asquith Commission on the then Higher Education. Asquith Commission proposed among other things, the establishment of University Colleges in affiliation with the University of London. Elliot Commission published two reports of which the majority had it that two University Colleges in the Gold Coast (Ghana) and Nigeria should be set up and the minority report indicated that one University College should be set up for British West Africa. The minority report was accepted by the British Government and established it at Ibadan in Nigeria. Based on the refusal of the people of the Gold Coast to accept the recommendation, the British Government reviewed its decision and agreed to set up the University College of the Gold Coast now University of Ghana.

There are myriad problems that affect students' attitude to the use of Information Communication Technology (ICT) facilities on campus. Empirical evidence is the slow Internet connectivity at the ICT center. It is quite frustrating to use the desktop computers at the University of Ghana Graduate School to access the Internet for research work because it is very slow. Students spend too much time on the computers, trying to get to a particular website for relevant information to aid research works. This affects students' attitude towards access to Internet via the desktop computers. Consequently, few students actually use the computers at the Graduate School to access the Internet. For instance having access to the desktops at the ICT center is not easy. One has to battle with the issue of distance and the limited number of ICT equipment at the centre. The ICT center is opened to students at $8.30 \mathrm{am}$ and closes at $4.30 \mathrm{pm}$ during week days but it is closed during weekends. Graduate students browse for only a few hours a day, apart from the fact that they do not have access to the computers at the Graduate School during weekends. Graduate students are therefore handicapped when they depend on this facility to search for information for their research works. Hence, it is a small section of graduate students who visit the center to use the facility since a sizeable number of graduate students have acquired their own laptops in order to access the Internet for their research works, anytime and at anywhere.

Little attention has been given in literature to acceptance of WIMD by users even though there has been an increasing amount of wireless mobile activity. A study on WIMD user acceptance was therefore good enough in providing useful information, considering the young stage of WIMD development and implementation (Lu, et al., 2003).

\section{Statement of the Problem}

Access to relevant information is one of the key concerns of many students who are research-oriented. However, students of the University of Ghana and in most developing countries face many challenges in terms of access to and use of technology for learning and research. This becomes even more acute, especially at the postgraduate level where research is a major component and access to information, particularly journals (e-journals) is very key. Putzer and Park (2012) postulate that, a technological device such as the smartphone and its corresponding interface should suit the necessities of the functions that a device is intended to support. This is significant primarily because not every mobile device can support salient functions, and one of the fundamental keys to adoption is whether the particular device and the user interface meet the clinician's requirements for effectiveness, screen size for readability, and suitability for other related functions that may be needed. Thus, the researcher is of the view that if the salient functions of mobile devices do not support readability, storage of retrieved documents and effective academic research works etc, graduate students will have a negative attitude towards the use of the Internet via mobile devices.

Alzaidiyeen et al. (2011) postulated that the complexity of a technology is the inhibitor that discourages the adoption of an innovation. Users are concerned with the effort required to use applications (such as mobile commerce and online banking) and the complexity of the process involved. A study conducted at the University of Sains, Malaysia, indicates that there is a statistically significant difference in the perceived ease of use of mobile devices between males and females, with results favouring males more than females (a Mean (M=3.68) with Standard Deviation $(\mathrm{SD}=0.67)$ while females' group reported a Mean $(\mathrm{M}=3.37)$ with Standard Deviation $(\mathrm{SD}=$ 0.51). In an academic setting like the University of Ghana, it is a cause of concern if a significant number of female 
graduate students perceive the ease of use of mobile devices as complex, since it will be difficult accessing the Internet for academic information to support research. Putzer and Park (2012), older physicians with considerable clinical experience need a broad personal experience with a device such as a smartphone along with superior technological experience before they will accept and adopt a new mobile technology. Thus, it is the researcher's view that unless older graduate students have a wider technological experience, they will not accept and adopt the use of mobile devices in accessing academic information on the Internet.

Aboelmaged (2010) opines that some challenges of mobile devices are inability to use some application software on most mobile devices, slow Internet connectivity and inability to store bulky files on most of them etc. This becomes a concern as most of these mobile devices have low memory storage capacities which make it extremely difficult for users to download and store relevant information. Moreover, some software like word processors and other statistical applications are mostly not supported by these mobile devices. Thus, the research was undertaken to ascertain graduate students' attitude, perceived ease of use, perceived usefulness and challenges of using the Internet via mobile devices so as to come out with some findings on ways to improve upon the use of the Internet via mobile devices among graduate students of the University of Ghana.

\section{Purpose of the Study}

The purpose of the study was to ascertain the attitude, perceived ease of use and evaluate the use of the Internet via mobile devices by graduate students of the University of Ghana, with a view to identifying problems and making suggestions for their resolution.

\section{Objectives of the Study}

The following were the specific objectives:

i. $\quad$ To find out the challenges students face using mobile devices for Internet access

ii. To make recommendations to enhance the adoption of the Internet via mobile devices among students

\section{Research Questions}

i. What are the challenges graduate students face when using mobile devices to access the Internet?

ii. What are the recommendations to enhance the adoption of the Internet via mobile devices by graduate students?

\section{Significance of the Study}

The study will be of significance to the University of Ghana (UG), students, academia and the information profession. To the UG, this study through its findings and results will help the authorities to make the right input of technologies into the university system to help students to access information for assignments and research work as well as disseminate information on the UG campus.

To academia, it will help academic institutions in tackling the issue of information dissemination and accessibility through the Internet. This is supported by the uses of PDAs as stated by Alzaidiyeen et al. (2011). Accordingly, Alzaidiyeen et al. (2011) state that PDAs are used for the following: they enable learning to occur virtually anywhere and anytime, they can be used to collect data about various subjects, they are useful tools for sharing information among students via a wireless network, they can serve as channels of communication, they are great tools to improve students' learning vocabulary and they have a positive role in improving students' collaboration. The research will also be of use to students because its findings, if acted upon by the University and academia, will help solve the numerous challenges students face in their attempt to use the Internet for academic work, especially research. For example the UG authorities should consider the introduction of the use of the Internet via mobile devices in teaching and learning at all levels and lecturers must encourage their students to make use of PDAs as learning tools. This will give the students considerable experience and exposure to the mobile devices especially during their graduate programmes which will also affect their adoption of the technology.

Finally, the findings of the study would provide useful suggestions for Information Professionals like librarians in their efforts to enhance information services delivery among students on University of Ghana campus. Mobile devices for Internet services when encouraged will provide links to electronic publications, open repositories and the reuse of Online Public Access Catalogue (OPAC) data by external databases and sometimes publicly available databases, such as Open WorldCAT (Cummings et al., 2010).

\section{Scope of the Study}

The study will be conducted within the confines of UG main campus, focusing on the use of the Internet via mobile devices by graduate students of the University for academic work. The specific variables covered were attitude, perceived ease of use, actual use of mobile devices and challenges within the context of the WIMD model. 


\section{Conceptual Framework}

This study adopted the Technology Acceptance Model for wireless Internet (TAM for wireless Internet) via mobile devices alluded to by Lu et al. (2003) which was originally propounded by Davis (1989). Several studies centered on the adoption of mobile services were based on TAM for wireless Internet which was originally meant to predict users' acceptance of information technology and its use on the job. In TAM for wireless Internet, user acceptance is determined by attitude towards use and intention to use instead of actual use, because Wireless Internet via Mobile Devices (WIMD) is at an infant stage, defined by restricted adoption and use.

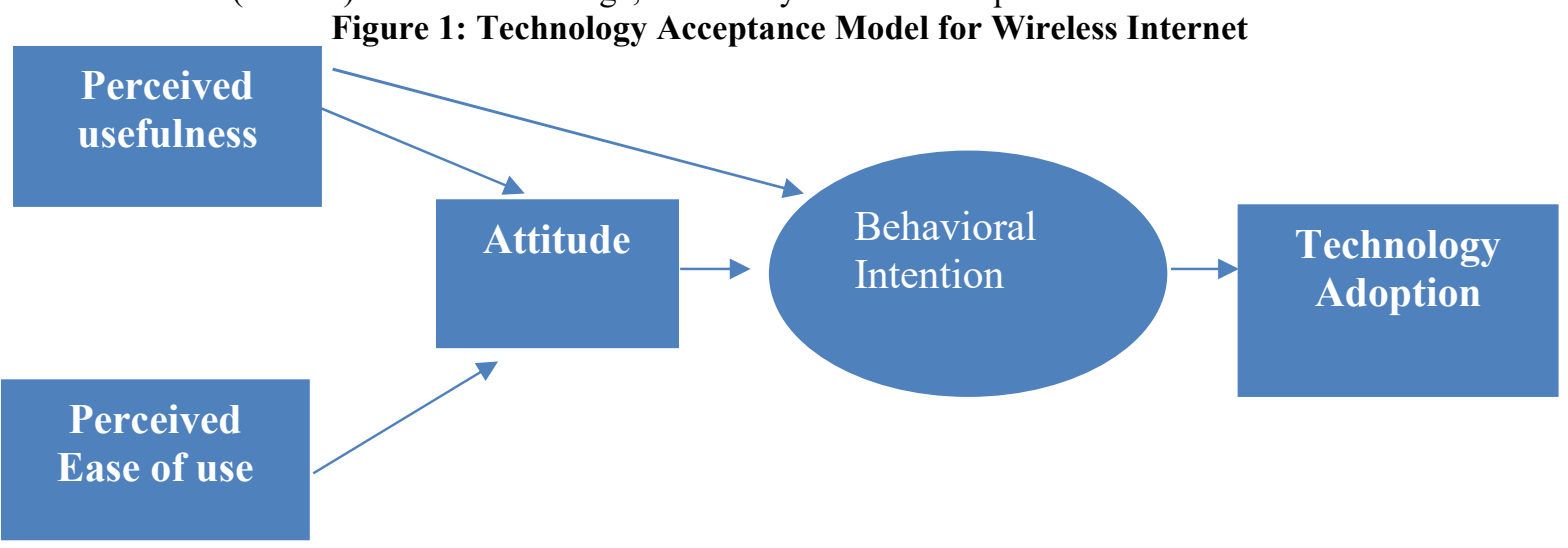

Source: Lu et al. (2003).

Attitude towards use in TAM model influences one's intention to adopt a particular system. Before a system is improved upon, users usually are most likely to form their own beliefs and attitudes as regards the system. Thus, in consumer research, attitude is considered as the most important construct. It is used to foretell the likelihood of a consumer adopting a technology. Currently, consumers have formed favourable or unfavourable attitude about any new technology, irrespective of the fact that they have either used the technology or not. It is important to investigate attitude towards WIMD and how it relates with intention to use a system in order to predict usage behaviour. It is hypothesized that attitude to WIMD will have a considerable constructive outcome on intent to employ WIMD. Perceived usefulness in TAM for wireless Internet was from the beginning used to refer to the productivity, performance and effectiveness of a job. Perceived usefulness directly influences one's intentions to use a system more than attitude. Attributes of future consequences are improved productivity, effectiveness, job performance or satisfaction. The consequent outcome of one's career prospects or social status is referred to as long term consequence. Behavioural intention in using a technology depends on perceived near-term usefulness, perceived long-term usefulness and perceived ease of use. Perceived near-term usefulness of WIMD will have a considerable positive consequence on attitude to using WIMD; perceived long-term usefulness of WIMD will have a considerable positive consequence on attitude to using WIMD; perceived near-term usefulness of WIMD will have a considerable positive consequence on intent to use WIMD; perceived long-term usefulness of WIMD will have a considerable positive consequence on intent to use WIMD.

Perceived ease of use also influences one's attitude towards use in the TAM for wireless Internet. Perceived ease of use refers to the mental effort engaged in using a system. When perceived ease of use is improved, it may result in improved performance. While advance performance defines perceived usefulness that is the same to nearterm usefulness, perceived ease of use will have a nonstop positive result on perceived near-term usefulness. For any up and coming Information Technology/Information System, perceived ease of use is the main determinant of users' adoption and usage behavior. In explaining perceived usefulness and the attitude towards using WIMD the following were hypothesized; perceived ease of using WIMD will have a significant positive result on attitude to using WIMD; perceived ease of using WIMD will have a significant positive result on perceived near-term usefulness of WIMD. The idea behind these associations is that the ease of use of technology and its usefulness will positively influence the intended users' attitude and intention towards using the technology. As a result the use of technology will increase (Lu et al., 2003). Thus, if UG graduate students perceive the use of Internet via mobile devices as easy and their attitude towards these facilities is positive, they will adopt and use the Internet via their mobile devices for both academic and personal works.

\section{Use of the Internet via Mobile Devices}

Out of a total of 6,767,805,208 global Internet users, 3,808,070,503 Internet users are in Asia. Internet users have grown from 133,900 in year 2000 to $18,500,000$ in year 2009. Pakistan's government encouraged foreign investors to invest in Information Technology (IT) infrastructure and broadband. Despite all efforts, educational institutions do not use and take advantage of the key significance of Internet in their academic and research work. While Internet use is 10.6 percent in Pakistan; it is 32 percent in Iran, 29.21 percent in Saudi Arabia, 62 percent in 
Malaysia, 86 percent in United Arab Emirates (UAE) and 12.5 percent in Indonesia (Abbasi et al., 2011). Thus, despite the huge investments in IT, if nothing is done to improve its ease of use, users will refuse to adopt mobile devices to use the Internet. Longe et al. (2009) also opine that Africa now boasts of over 50 million Internet users, representing about $5 \%$ Internet diffusion rate on the continent. Some parts of Sub-Saharan Africa, particularly West Africa is taking the lead to bridge the digital divide by connecting to other parts of the world through fiberoptic cables. Countries such as Seychelles and Mauritius have benefitted from the advantage of established infrastructure and have been able to rise above teething problems ensuing from ICT spread.

Armah (2010) asserts that, the use of the Internet has enabled many users in Ghana to access the Online Public Access Catalogue (OPAC) and databases. Electronic (e) - mail is used to offer services such as reference services, inter-library loan and document delivery. Through e-mail, there is a much more improved link among academic and research libraries in Ghana. Internet has also improved the exchange of ideas and collaboration among students and researchers. The researcher is of the view that certain factors induced the less use of the Internet in Pakistan, as against Internet use in Ghana and one of these could be the culture of the people which affects their attitude. It is very strange that researchers in the two different parts of the world vary in terms of their level of use of the Internet in accessing e-journals for research work. There is every reason to use mobile devices to access the Internet. Apart from using mobile devices to access materials either in the physical library or virtual library, they could be used for reference services.

According to Advanced Information Technology Institute (2008), a research was conducted in some selected districts of the Central Region in Ghana, with specific emphasis on the fishermen of Moree and it was realized that fishermen used mobile phones to communicate with their agents and customers in order to know where prices of fish were most competitive. In the same vein the librarian could use a mobile device for inter-library loan for effective service. This is because as posited by TAM for wireless Internet, once a librarian forms a positive perception about the Internet via mobile devices for basic services like electronic-mail, Short Messages System (SMS), etc their attitude towards the technology is going to be positive, which will go a long way in adopting such technology for other advanced library services like the OPAC, inter-library loan etc.

Chae and Kim (2003) posit that the Mobile Internet System (MIS) is different from Stationary Internet System. The MIS provides a lesser level of available system resources. Second, there is immediate connectivity which allows mobile Internet use in times of need anywhere and anytime. Third, it is more personal compared to the stationary Internet. These characteristics influence customers' preference for services. In commerce, customers prefer to buy low risk rather than high risk products for several reasons. Users can get low risk products conveniently with minimal search costs. Mobile Internet users consider using SMS services in the communication domain because of instant connectivity and privacy given to them. Also, consumers prefer more individually customized content on the mobile Internet because it gives more privacy than that of the stationary Internet. There is no doubt in the view of the researcher that users of mobile devices would use mobile devices to access the Internet because, it allows a relatively high customization of information and some level of privacy for the user, compared to desktop computers. Frimpong (2009) asserts that in year 2007, in a household and individual user survey in Ghana, it was revealed that the level of use of mobile phones was very high in urban centers than in rural areas. Sixty (60) percent of Ghanaians, whose ages were 16 and above had active Subscriber Identity Module (SIM) cards which they used to communicate. The researcher is thus of the view that, if the University of Ghana acquires a software that allows its students to access materials from its physical library, no matter where graduate students are in Ghana, more of them will use mobile devices to access information for their research works.

Gamos (2009) posits that in the social and business fronts, mobile devices are of great value. They are used to contact people during emergencies. They are also used to access news and entertainment. In Ghana mobile devices are mostly used to access information on remittances and job opportunities. In the view of the researcher, mobile devices could also be used to inform users of UG library when books borrowed from the library are long overdue and if there are some charges; they are made known to users.

Mbambo-Thata (2010), the University of South Africa (UNISA) library offered mobile phone services in the year 2008 to its learners. Since UNISA is an Open Distance Learning Institution (ODLI), its library service has been structured to reach UNISA students irrespective of wherever they find themselves. UNISA uses SMS to get students informed about registration, examinations, assignments and other similar important pieces of information. UNISA library also acquired and used AirPAC, a product of Innovative Interfaces Inc., to customize the website of the library for small screens so that students and staff with web-enabled mobile phones can access the library website, request learning documents, search some databases and generally manage their patron records. The product was advertised very well through both print and electronic media to its numerous students who lived in the towns and villages and probably had web-enabled phones. A video was used to introduce clients, besides newsletter, posters and presentations to faculty. The library staff were also informed and educated on AirPAC to equip them to effectively introduce their clients to another tool to reach the library. All these were put in place to ensure that users of UNISA library were properly equipped to effectively and efficiently access library materials which was lauded by many. 
Okello-Obura (2010) posits that, one cannot access e-resources without adequate computer skills. Growth in society's access to information via ICT has changed students' perception of what the library has to offer. If libraries are to preserve their significance in the cycle of needs of students, then they must adapt and change. Students' ability to find and retrieve information effectively is a transferable skill, useful for their future life as well as enabling the positive and successful use of the electronic resources while at school. Some researchers are of the view that in this digital era any student at the higher level, who intends to achieve good results, should have the ability to explore the digital environment by acquiring and practicing the skills necessary to exploit the e-resources. These skills include knowledge of the structure of the database, the instructions that the searcher must enter into the mobile device and an understanding of the way these instructions are linked to one another.

Okello-Obura (2010) continues by indicating that, some researchers have indicated that skills required to access the maximum potential of electronic resources are much greater than those required for searching printed sources. Computer skills give library users a practical understanding of how their computers and printers operate, how to troubleshoot problems, how to locate an Internet website and a host of other technology-based skills that help the library user to be more successful in the technological world. In the opinion of the researcher, users of mobile devices can actually download e-materials which are relevant to their work because they need no special skills in doing that when using mobile devices.

Cummings et. al (2010) is of the view that i-Phone, iPod Touch, most modern BlackBerrys and Palm Pre have merged easy downloading, storing and viewing of PDF documents, Microsoft Office files and spreadsheet formats. Thus, developments in future will aid many users of academic libraries to easily use library services using the handheld mobile computing devices. Also these devices are able to connect to the Internet faster, using Wi-Fi connections than using slower and more expensive cell phone connections. A user that is connecting to an academic library website through a mobile device will most likely have a particular task in mind. These tasks may probably differ a little by institution but include tasks related to the catalog interface. Thus the researcher is of the view that lack of access to appropriate mobile devices affects its use for Internet access, a view which Bruner and Kumar (2003) share.

\section{Challenges in the Use of Mobile Devices for Internet Access}

The Web is indeed huge. In fact it is so big that it is hard to get an accurate count of its size. It was approximated in 2004 that the Web comprised more than 10 billion pages, with an average page size of 500KB. Deep web pages cannot be found by casual, routine surfing. When surfers access information from a specific database the required pages are served with speed to the user within seconds. The Web is dynamic. Web Pages do vary their content by themselves regularly. About $35 \%$ of all web pages vary in the course of their study and also larger pages vary more often and to a large extent than their smaller counterparts. The web is self-organized. There are no standards and nobody to monitor content, structure and format. Users rarely scrutinize beyond the first 10-20 documents retrieved. Even small web collections are too large for researchers to catalogue, count and create estimate of the exact and recall numerators and denominators for a number of queries (Langville and Meyer, 2006). Thus, looking at how huge electronic data is on the $\mathrm{Web}$ and how dynamic it is, it is important that users who use mobile devices to access e-resources understand the Web, be familiar with the interface design on a mobile device, have the necessary skills and be able to access the right and relevant information based on the key words in a query. The researcher thinks that based on these, web retrieval process is a huge daunting task compared to the manual retrieval process and therefore the role of the information professional has become even more essential.

Frempong (2009) opines that, the high cost of handset and subscription associated with the use of mobile telephony for business activities, is a cause of concern. Majority of Micro and Small Enterprises (MSEs) including non-subscribers consider the cost of subscription as an obstacle to accessing mobile services. Mobile Telephone Operators have little or no control over the cost of handsets. Private companies and individuals cost their handset products based on the market situation and the exchange rate of the cedi. Thus the researcher is of the view that, the high cost of handsets and subscription has contributed to the increased cost of Internet access via mobile devices among graduate students of UG. Also, there is the issue of poor quality of mobile service in Ghana. In an urban center like Accra, where UG is situated, the volume of traffic is so high that it causes congestion and poor reception of Internet access. Thus, graduate students who use the Internet via mobile devices are bound to be confronted with the problem of congestion, poor reception of Internet access and inexplicable subtraction of credits particularly during credit transfers.

According to Frempong (2009), the Communication Service Tax of 6 percent imposed by the government of Ghana on users of mobile devices, which became operational in June 2008, was feared to increase mobile telephone tariffs, since the mobile operators were likely to pass on the tax to their consumers. This action by Ghana government will go against the drive of the market to reduce the price of Internet access via mobile devices by graduate students.

Gamos (2009), with regard to the use of Broadband in Africa, there are a small number of users and a slow rise in the use of broadband. In 2007, statistics of broadband users across Africa were as follows: Ghana- $0.07 \%$, 
Kenya- $0.05 \%$, Senegal- $0.3 \%$, South Africa- $0.8 \%$, Uganda- $0.01 \%$. Broadband is hampered by the high cost of broadband; high cost of international bandwidth; failure to unbundle local loops. The continued failure to unbundle copper local loops controlled by incumbent operators has prevented competition. In Ghana, for example, it can cost a user $\$ 532.48$ to download one gigabyte of data over one operator's GPRS network and taxes on mobile services are generally considered too high and make SMS comparatively expensive. The high price acts as a disincentive to its use. Large sections of the population are not literate and cannot engage with text-based content. Many users will require m-content in local languages, moreover, they may have a preference for local content. At present, little content is created in local languages and few handsets support it. The researcher is thus of the view that anytime UG is not able to acquire a bigger bandwidth, it would be extremely difficult for graduate students to retrieve information from UG Balme library.

Okello-Obura (2010) asserts that, the question of knowing how to use a computer will remain a challenge to most students in developing countries while access is a problem. Some of the problems of library automation are slow Internet connectivity, unsatisfactory networked computers, poor formulation of search strategies, ignorance of the difference between refereed and non-refereed journals, inadequate budgets and access to e-journals. The researcher thinks that with the above problems of library automation, it would be almost impossible to set up an automated library that will effectively and efficiently meet the needs of graduate students in African universities. Mbambo-Thata (2010), Ball State University Library (BSUL) in year 2004 introduced mobile phone to monitor and evaluate its services but realized challenges such as, the small screen size of most mobile phones being a limitation to viewing large images; limited memory of mobile devices; slow mobile phones wireless connectivity and the BSUL site had big images which were so difficult to download without Java on the mobile phones. In the view of the researcher, graduate students may not be able to read what they download because of small screen size of most mobile devices. Even if they are able, they will be slow in reading because of the fact that they have to align what they read to the left and to the right, one after the other, in the process of reading. Also, they will spend too much time retrieving information on the Internet.

Eke (2010) posits that, in e-learning instructors need to spend a great deal of time and effort re-engineering the course to change it for online delivery. There are also limitations to online learners at workplaces as well as at family level. E-learning technical problems that hinder instructor's activities are 'the lack of course prototypes and software standards that raise the need for a common course development platform'. Staff's lack of technical expertise is also a hindrance. Unreliable technology affects instructor's ability to monitor students' activities. When designing e-learning courses, instructors must take note of student's technical challenges such as bandwidth and computer hardware. A small bandwidth impacts negatively on downloading and that can negatively affect learning. Some learners fear technology and so they are not attracted to e-learning. Lack of exposure to technology can as well scare away some learners without they first trying to attempt it. Lack of finances can also serve as a threat to the realization of e-learning. Poverty is one of the key barriers to ICT implementation in Africa, because ICT in Africa is very expensive than in developed countries. The researcher shares the view that the size of the bandwidth can either enhance or limit downloading of e-materials. On the other hand the fear of technology is not prevalent among graduate students, because most of them use mobile phones for communication and other purposes.

Akakpo (2008), it is hard to come across telecommunication facility in rural areas in Ghana. To reach rural areas, one must connect using a wireless infrastructure. Rural areas with coverage are areas with mobile coverage with Ghana Telecom's Fixed Cellular Terminal (FCT). Though the widespread nature of wireless access possibly should improve connectivity, it is underutilized because of the limited infrastructure which is low in quality. The cost of buying bandwidth and satellite bandwidth are high in Ghana. Thus it is an expensive venture sending Internet to rural areas since there is lack of last mile infrastructure and other facilities. The SAT3 fibre in the West coast of Africa costs a GISPA-registered Internet Service Provider \$4,050 per Mbit. In the year 2008, 20 hours of Internet use cost $\$ 20$ compared to $\$ 60$ in year 2001. There is also the problem of lack of a steady, reliable power supply and the hardest hit is the rural folks. In areas where there is no electricity, sending connectivity to such areas implies buying a very expensive generator. There is also the problem of lack of capital to secure cost valued consumer and electronic equipment. The researcher is of the view that the use of computers at the Graduate School IT center can introduce major limitations to accessing the Internet, such as, cost of bandwidth and cost of electronic equipment. However, when using mobile devices to access the Internet, the above challenges which are common with computers may not hold.

\section{Graduate Students' Use of the Internet via Mobile Devices}

School of Research and Graduate Studies (2011) posits that a graduate student must have a good first degree in a related field of study at a recognized University. For further studies, graduate students must take an entrance examination and/or an interview at a Department/Institute/Center. According to School of Research and Graduate Studies (2009), some course descriptions of programmes in the humanities are M.A/M.PHIL English; M.A/M.PHIL Linguistics; M.A/M.PHIL French; M.PHIL Economics; M.A Economic Policy Management; M.A 
Library/Archival Studies; M.A/MPHIL Development Studies etc. Kwapong (2009) the use of Information Communication Technology (ICT) [Internet via mobile devices] is for purposes of facilitating education, health, agriculture etc through equitable and affordable access. The uninterrupted growth of new technologies and their functions could improve the quality of life for all, irrespective of the geographical location and gender. Those who defend the use of Internet via mobile devices for development and most especially for women empowerment argue that women no longer have the comfort to disregard them. An appraisal of 150 distance education programs in Sub-Saharan Africa has revealed that the print mode continues to be more dependable, sustainable, and widely used than online and Web based methods of learning. This may well be as a result of limited ICT infrastructural development and unreliability of electricity in most parts of the sub-region. The researcher is of the view that when school is in session, the use of the Internet via mobile devices by graduate students could facilitate research works. However, when students are on vacation, their locations would determine their ability to access information for research works. For instance those in the urban areas usually are privy to these ICT infrastructure and reliable source of energy which is not so in the rural areas.

Longe et al. (2009) opine that one of the most popular cyber crimes is the act of prostitution through the use of the Internet. The stakeholders involved in the business of prostitution are sex workers who work in any or all sphere of the sex industry. These constitute anyone from pornography film stars to escort mail order brides, and prostitutes. Most clients of these prostitutes are tourists from the Western world. These tourists get hooked up by the Internet when they seek information regarding travel location and or destination. They are either misled onto websites that advertise sex tour, or practically offered these baits as travel incentives. Some graduate students could therefore fall victim to prostitution and other cyber-crimes because of their constant use of the Internet via mobile devices for their academic works. This has however become a disincentive for many students who use the Internet.

\section{Research Design}

The research design that was used to examine the use of the Internet via mobile devices among graduate students of the University of Ghana was survey research. The reason is that this research design allows the collection of a large amount of data from a sizable population in a highly economic way. The quantitative research approach was embarked upon - this research is sustained by the procedural values of positivism and held fast to the standards of stringent research design developed prior to the commencement of the research. It employs quantitative measurement and statistical analysis (Sarantakos, 1993). According to Busha and Harter (1986), it is one of the oldest and widely used methods in the Social Sciences. They further indicated that survey research method is the most widely used for any research work in librarianship. Alreck and Settle (1985) described survey research as comprehensive, versatile and efficient. Survey research provides extensive quantitative data relatively cheaper while broad generalization can be made from comparatively smaller number of observation as long as probability sampling methods are used (Blumer and Warwick, 1993).

\section{Selection of the Case}

The researcher decided to select UG as the study area because it is the first among all public Ghanaian Universities to be established in Ghana and as a result the findings of this research could fairly be applied in other Universities in Ghana. The compositions of students in UG are Diplomats, Undergraduates and Post-graduates students but the researcher decided to make post-graduates his unit of study because among the three groups of students, graduate students are used to academic research, hence the decision of the researcher to make graduate students his unit of study.

\section{Population of the Study}

The population for the study is graduate students of the University of Ghana, a homogeneous group, whose population in year 2009/2010 stood at 2,876 (University of Ghana Basic Statistics, 2010). Koul (2001) postulates that population is a group of human entities and non-human entities like objects and institutions of learning. Population parameter is the type of population which the researcher wants to investigate. A group could be a sample as well as a population at a given time. Sometimes researchers prefer to study the whole group of interest to them, which is a difficult thing to do. Populations that attract attention are mostly bigger, varied and scattered over a vast territorial area. Finding out and reaching out to the entire units of a population can be time-consuming and expensive. This explains why samples are chosen to study.

\section{Sample Size}

A sample size is a small unit of a population that is chosen to study and analyze; that is, a sample is a subset of a population, selected to represent that population. The main goal is to get a representative sample or a small collection of units from a much larger collection or population, study the smaller group and produce accurate generalizations about the larger group. The right sample size depends on the nature of a population and the purpose 
of a study. Large samples become more representative of a population thereby making the results more reliable and valid (Nwana, 1982). Thus some members of a population constitute a sample. The quest for research has created the need for an efficient method of determining the sample size to represent a given population (Krejcie and Morgan, 1970).

Khan (2006), there are various ways of determining the sample size needed to achieve representativeness for a given population. One is to select a minimum of $10 \%$ of the population. This view is shared by Alreck and Settle (1985) who expressed the view that, occasionally it was necessary to have a more than $10 \%$ sample of a population for confidence building, provided that the resulting sample was less than approximately 1,000. Therefore, for a 1,000 units population, an experienced researcher may decide to make do with $10 \%$ sample size. For a 5,000 population, the least sample size may be 100 and the maximum may be almost 500 , or $10 \%$. Thus, for a population of 2,876 , a $10 \%$ sample size was chosen for this study.

\section{Sampling Technique}

Convenience sampling was used for the study. In convenience sampling, all the subjects for the study that the researcher happened to meet were considered. The process was continued until the required sample size was obtained. The issue about convenience sampling is that subjects who can easily be reached might vary from the usual population with regard to the significant variables to be measured. Thus, they do not represent the entire population. Nonetheless, in researches where convenience sampling is used, less emphasis is placed on representativeness (Sarantakos, 1993). According to Neuman (2007), convenience sampling is simple to construct, evaluate, cheap and gives quick results. Subjects for the study were not available at a go, so the researcher selected respondents who were available at the UG graduate school ICT center and were willing to participate in the study. When a student hinted that he was a graduate student, he automatically qualified to take part in the research work by way of answering a questionnaire. The reason being that all graduate students whether in year one, two or three are seriously engaged in assignments and formal research works, which are key components of graduate academic work.

\section{Instrumentation}

In information science research, various data collection instruments are used. These data collection instruments consist of questionnaires, interviews, observations etc. Each instrument has its strengths and weaknesses (Aina, 2002). The desired level of data accuracy and relevance, economy of resources, efficiency and completeness informs the actual technique to use. In this study, questionnaire was used to collect data. According to Stark and Roberts (1996), a questionnaire is a formally ordered outline of questions presented in a uniform way to a number of persons. The questionnaire was used because it was hoped that the questions would represent both facts and opinions which have many advantages. Fraenkel and Wallen (2000) posit that, survey questions should be measured by four main standards. They are 'Is this a question that can be asked exactly the way it is written?'; 'Is this a question that will mean the same thing to everyone?'; 'Is this a question that people can answer? and 'Is this a question that people will be willing to answer, given the data collection procedures?.' 'Yes' should be the answer to each of the above questions. If any of the standards is violated in a survey questionnaire, then the questionnaire should be rewritten. These standards were the basic guide for the designing of the questionnaire used in this study. To most respondents questionnaires are very popular and convenient. The application of questionnaire minimizes bias and undue influence from both respondents and researcher.

The questionnaire had five sections which were captioned under the following: Section A was on attitude of graduate students towards the use of Internet via mobile devices, which covered variables such as mobile devices used by graduate students, how long mobile devices have been used, whether students would like to use mobile devices to access the Internet, what students use the Internet for among others. Section B dealt with perceived ease of use of Internet via mobile devices, which also covered variables such as whether it was easier to access the Internet via mobile devices. Section $\mathrm{C}$ was on actual use of Internet via mobile devices, which looked at variables such as how often the Internet is used via mobile devices, the benefits derived thereof among others and finally Section D dealt with challenges students face in using mobile devices to access the Internet and the variable looked at included obstacles to the use of mobile devices in accessing the Internet which comprised screen size, slow transmission speed, memory capacity etc.

The questionnaire contained both closed-ended and open-ended questions. Both types of questions have their strengths and weaknesses. Closed-ended questions are easy to administer and analyze and a researcher needs to tabulate the number of responses to each alternative in order to understand what the respondents think about an issue. Respondents are usually less willing to create a written response than to simply 'check off or circle the right alternative' (Fraenkel and Wallen, 2000). In open-ended questions subjects can reply as they like and they are not limited to a single alternative. Also, responses are constructed and written by respondents. The major benefits of open-ended questions are that respondents have the liberty to reveal their attitudes and motives and to qualify or explain their answers. Open-ended questions are richer and complete in response. The questionnaire was used as 
an instrument for the study because of the large sample size that the researcher had to deal with, for in 10 minutes, a respondent could complete a questionnaire. Also, it was less expensive to administer and it offered great anonymity.

\section{Mode of Data Collection}

The researcher administered the questionnaires at the ICT Center at the graduate school. This was because it was not easy to identify a graduate student among all other students. Besides, they were fewer in terms of numbers and scattered all over the campus, making it difficult to easily come across one. The researcher politely approached graduate students upon their arrival at the Graduate School and requested for their assistance to enable him collect data on the use of the Internet via mobile devices among UG graduate students. The respondents were also assured of confidentiality and as a result, many of them accepted to answer the questionnaires immediately, while others took them away and promised to give them to the ICT attendant at the graduate school for collection. Thus the researcher gave a questionnaire to each student who accepted to participate in the study, until the two hundred and eighty-eight questionnaires were all exhausted. Some declined to participate in the study, citing reasons as being busy with their assignments and no time to waste. After one week, students were no longer visiting the Graduate School ICT center frequently to access the Internet so the researcher went back to the attendant to collect the returned questionnaires. This was because the second semester examinations were very close at the time, so it was difficult getting them at the Graduate School ICT center. The researcher therefore arranged with six students; two assigned to each of the three main Graduate Hostels namely: Legon Hall Annex C, Valco Hall Phase 1 and Phase 2 , to administer the questionnaires in the halls.

The researcher then trained the six students to administer the questionnaires in Legon Hall Annex C, Valco Phase 1 and Valco Phase 2, in an attempt to collect the data in time before students go on vacation. The research assistants therefore approached potential respondents in the graduate halls of residence and explained the purpose of the study. They also assured them of confidentiality and were civil towards them, so that they would freely provide the much needed information for the research. Some students readily answered the questions and gave them back to the research assistants immediately, while others kept them close to two weeks. The research assistants went back to collect the rest of the data each day of the week. In all two hundred and eighty-eight questionnaires were distributed to the subjects of this study but two hundred and forty-four questionnaires were received.

\section{Method of Data Analysis and Presentation of Results}

The data was analyzed by the use of the Statistical Package for Social Sciences (SPSS). The best tools to summarize the data and create the right tables, graphs and evaluate the relationships among variables are the computer and the SPSS package (Tagoe, 2009). The results were presented in tables showing frequencies and percentages. The presentation of results was done in line with the stated objectives as follows: attitude of graduate students towards the use of the Internet via mobile devices; perceived ease of use of Internet via mobile devices by graduate students; level of use of Internet via mobile devices by graduate students; challenges in the use of mobile devices for Internet access and recommendations to enhance the adoption of the Internet via mobile devices.

\section{Problems Encountered and Limitations of the Study}

Some students were not ready to give the researcher their attention and some gave very rude remarks on approaching them but the researcher ignored the comments. On many occasions the researcher had to call some respondents, just to collect data from them but they kept postponing the time. Finally, the researcher arranged with respondents as to when to meet them. On one occasion, the researcher had to stay on campus till 11.00 p.m to collect data. Generally, the results of the data was not affected in anyway because, all graduate students whom the researcher interacted with, had at least one mobile device or the other, which they used to access the Internet.

\section{Gender of Respondents}

As part of the background information, the researcher tried to find out the gender of the respondents. The results revealed that 151 representing $61.9 \%$ of the respondents were males as compared to the females who were 93 representing $38.1 \%$ of the total sample for the study.

Table 1 Gender use of Internet via Mobile Devices

\begin{tabular}{lcccc}
\hline \multicolumn{1}{c}{ Use of Internet via Mobile Devices } & \multicolumn{2}{c}{ Males } & \multicolumn{2}{c}{ Females } \\
\hline Yes & Frequency & Percent & Frequency & Percent \\
No & 102 & 67.5 & 65 & 69.9 \\
\hline Total & 49 & 32.5 & 28 & 30.1 \\
\hline
\end{tabular}

Source: Field work, 2020.

From Table 1, it was revealed that out of the 244 respondents, $102(67.5 \%)$ of male graduate students used 
mobile devices for Internet access while 49 (32.5\%) did not. As regards the female graduate students, it was revealed that $65(69.9 \%)$ used the mobile devices for Internet access while $28(30.1 \%)$ did not. The data shows that the number of female respondents who use the mobile devices for Internet access is slightly more than the number of male respondents who use the mobile devices for Internet access. One potential reason for more female respondents could be that females are more likely to be interested in the usage and acceptance of mobile devices as established by Banda (2011) that more females used mobile phones than males.

\section{Level of Students}

The level of graduate students was sought to determine the number of academic years the students had spent so far in school. From the responses gathered from the respondents as indicated on Table 4.2, it was revealed that 184 $(75.4 \%)$ of the graduate students were in their second year of study (these were the total number of MPHIL, MBA and MPA students). $58(23.8 \%)$ were in their first year of study (these were the MA students), while $2(0.8 \%)$ of the graduate students were in the third year of study (these were the PHD students). This shows that the majority of the graduate students were in the second year of study.

Programme of Study and Faculty of Graduate Students

The researcher identified the relationship that existed between the programme of study and the faculty which graduate students were. The following are the results in Table 4.2.

Table 2: Programme of Study and Faculty of Graduate Students

\begin{tabular}{lccccc}
\hline \multicolumn{1}{c}{ Programme } & Arts & Science & Social studies & Business School & Total \\
\hline MA & $15(40.5 \%)$ & $3(7.1 \%)$ & $40(42.6 \%)$ & - & $58(23.8 \%)$ \\
MPHIL & $20(54.1 \%)$ & $38(90.5 \%)$ & $49(52.1 \%)$ & $6(8.5 \%)$ & $113(46.3 \%)$ \\
MBA & $1(2.7 \%)$ & - & $2(2.1 \%)$ & $63(88.7 \%)$ & $66(27 \%)$ \\
MPA & - & $1(2.4 \%)$ & $2(2.1 \%)$ & $2(2.8 \%)$ & $5(2 \%)$ \\
PHD & $1(2.7 \%)$ & - & $1(1.1 \%)$ & - & $2(0.8 \%)$ \\
\hline Total & $37(100 \%)$ & $42(100 \%)$ & $94(100 \%)$ & $71(100 \%)$ & $244(100 \%)$ \\
\hline
\end{tabular}

Source: Fieldwork, 2020

Table 2 shows the programme of study and faculty of graduate students. The MA graduate students in Arts, Science and Social Studies were $15(40.5 \%), 3(7.1 \%)$ and $40(42.6 \%)$ respectively. In addition, the MPHIL graduate students in Arts and Social Studies faculty were 20 (54.1\%) and 49 (52\%) respectively. This means that the MPHIL students belonging to the Social Studies faculty were more than those in the Arts and Science faculties.

\section{Access to Internet via Mobile Devices}

People want more specific information when they are mobile. Therefore, the content and service people used to access the Internet may be quite different from those used when they are in a fixed location. The ultimate value of using Internet via mobile device is to get the required content and services by taking advantage of their portability and accessibility (Goldman, 2000). Table 4.8 depicts the individual responses.

Table 3: Access to Internet via Mobile Devices

\begin{tabular}{lcccc} 
& \multicolumn{2}{c}{ Access to Internet } & \multicolumn{2}{c}{ Access to academic information } \\
& Frequency & Percent & Frequency & Percent \\
\cline { 2 - 5 } \multicolumn{1}{c}{ Remarks } & & & & 20 \\
Very easy & 18 & 7.4 & 100 & 8.2 \\
Easy & 86 & 35.2 & 57 & 23.4 \\
Somewhat easy & 59 & 24.2 & 20 & 8.2 \\
Difficult & 24 & 9.8 & 1 & 0.4 \\
Very difficult & 8 & 3.3 & 198 & 100 \\
\hline Total & 195 & 100 & & \\
\hline
\end{tabular}

Source: Field work, 2020.

It can be observed that $86(35.2 \%)$ of the respondents found it easy to access the Internet via the mobile devices while $59(24.2 \%)$ of the respondents found it somewhat easy.

Again, Table 3 shows that most of the graduate students of the University of Ghana use the Internet through their mobile devices to access academic information for their various studies. It could be observed that $100(41 \%)$ of the respondents found it easy to access academic information from the Internet via their mobile devices. This could be attributed to the research-oriented nature of their study. Furthermore 57 (23.4\%) of the respondent found it somewhat easy to use the Internet via mobile devices to search for information for their academic works. 
Types of Mobile Networks Used

In Ghana, there are five networks available to every citizen to choose from. The researcher thus sought to know which of the networks respondents were using in accessing the Internet via mobile devices.

Table 4.: Types of Networks Used

\begin{tabular}{lcc}
\hline Mobile Networks Used & Frequency & Percent \\
\hline Tigo & 17 & 7.0 \\
MTN & 122 & 50.0 \\
Vodafone & 24 & 9.8 \\
Airtel & 18 & 7.4 \\
Expresso & 1 & 0.4 \\
Tigo and MTN & 12 & 4.9 \\
MTN and Airtel & 13 & 5.3 \\
Airtel and Tigo & 1 & 0.4 \\
Vodafone and Airtel & 4 & 1.6 \\
Vodafone and Tigo & 15 & 6.1 \\
Expresso and Tigo & 17 & 7.0 \\
\hline Sourc:
\end{tabular}

Source: Field work, 2020.

Table 4. shows that all the respondents were using all the five networks available in the country. For the purpose of this research, it can be said that majority (50\%) of the respondents use MTN for browsing the Internet via mobile devices.

\section{Frequency of Internet Use via Mobile Devices}

One of the objectives of the study was to find how often respondents used Internet via mobile devices. With this objective, the researcher wanted to know the frequency of Internet use via mobile devices by graduate students. Responses received are shown in Table 4.10.

\section{Table 5: Frequency of Internet Use via Mobile Devices}

\begin{tabular}{lcc}
\hline Frequency of Internet use via mobile devices & Frequency & Percent \\
\hline Daily & 97 & 39.9 \\
Weekly & 42 & 17.2 \\
Few times in a month & 19 & 7.8 \\
Few times in a year & 8 & 3.3 \\
\hline Total & 166 & 100 \\
\hline
\end{tabular}

Source: Field work, 2020.

Table 5. Shows the frequency of the internet use via mobile devices. Out of the total population sampled, 97 $(39.8 \%)$ use the Internet via mobile devices daily, $42(17.2 \%)$ use the Internet via mobile devices weekly, 19 $(7.8 \%)$ use the Internet via mobile devices a few times in a month while $8(3.3 \%)$ of the respondents indicated that they use the Internet via mobile devices, a few times in year.

\section{Benefits Derived from Using Internet via Mobile Devices}

Mobile devices, especially cell phones, have experienced three-generation in development. The first generation provided the ability of mobile phone communications. The second generation improved the reception and enabled a range of sophisticated services to be offered by using the Global System for Mobile communications (GSM). The third generation offered wireless Internet access by using GPRS (General Packet Radio Service). With GRPS, data transmission speeds will expand from 9.6 or $14.4 \mathrm{kbps}$ in the GSM system to the current 115 kbps (Kenyon and Perkins, 2000). It can support a wide range of services ideal for mobile users, including unified messaging, eshopping, location-based, and time critical services (Dornan, 2001)). With the huge mobile subscriber base in China and the long habit of using mobile phones in various business activities, the potential for m-commerce is tremendous. Based on the objectives of the study and the assertions made by Kenyon and Perkins and Darrow and Harding, the researcher wanted to know from the respondents the benefits they derived from using the Internet via mobile devices. 
Table 6: Benefits of Internet Use via Mobile Devices

\begin{tabular}{lrr}
\hline Benefits & Frequency & Percent \\
\hline Broadening Knowledge & 51 & 20.9 \\
Convenience of search & 92 & 37.7 \\
Broadening of knowledge and quicker access to information & 2 & 0.8 \\
Broadening of knowledge and wider access to information & 2 & 0.8 \\
Convenience of search and wider access to information & 97 & 39.8 \\
\hline
\end{tabular}

\section{Source: Field work, 2020.}

Table 6 shows that 97 (39.8\%) respondents indicated that benefits derived from using mobile devices for Internet services was the convenience of search and wider access to information. In addition, $92(37.7 \%)$ claimed that the mobile devices were used to access Internet services because of the benefit of convenience in searching. Again, 51 (20.9\%) of the respondents indicated broadening knowledge, as the benefit of using mobile devices for Internet services.

\section{Challenges with Browsing the Internet via Mobile Devices}

As a follow up question, the researcher wanted to know if there are problems in accessing the Internet via mobile devices. In response, several reasons were given by the respondents. Among the reasons given were low phone capabilities, slow network connections, high Internet browsing charges by the service providers and the time spent in surfing the net via mobile devices. The respondents responded to the question regarding the challenges faced when accessing the Internet via mobile devices

\section{Table 7: Challenges of Internet Use via Mobile Devices}

\begin{tabular}{lrr}
\hline Challenges & Frequency & Percent \\
\hline Screen size & 115 & 47.1 \\
Memory capacity & 88 & 36.1 \\
Slow transmission speed & 7 & 2.9 \\
Lack of skill & 1 & 0.4 \\
Screen size, memory capacity and level of battery capacity & 2 & 0.8 \\
Screen size, memory capacity and slow transmission speed & 1 & 0.4 \\
Memory capacity, slow transmission speed and lack of skills & 29 & 11.9 \\
Screen size and memory capacity & 1 & 0.4 \\
\hline
\end{tabular}

Source: Field work, 2020.

Table 7 shows the challenges respondents face when using the Internet via mobile devices. From Table 4.12, $115(47.1 \%)$ of the respondents had the problem of screen size when using the Internet via mobile devices. It was also revealed that $88(36.1 \%)$ of the respondents found memory capacity as a major problem they faced when using the Internet via mobile devices

\section{Use of the Internet via Mobile Devices}

A major objective of the study was to find out the use of the Internet via mobile devices by the graduate students. The outcome of the investigation revealed that the use of the Internet via the mobile devices was quite high among the graduate students of the University of Ghana, Legon. This was obvious because, the Internet being an essential technology was very much needed in the academic world. Besides, the positive perception and attitude students have developed over the years from using mobile devices have led to the increased use of the technology. However, Boye (2007) opined that over ninety percent $(90 \%)$ of the students were aware that mobile phones could be used to access the Internet, but only ten percent $(10 \%)$ of them actually used it to search for information. This indicates that the majority did not explore the use of the mobile devices. A similar research conducted by Atiso (2002) on the use of the Internet facility revealed that, during the final year of students' academic research, the Internet is highly patronized. In Atiso's research, it was observed that though the Internet could be used for other things like films or music, students rather used the Internet via the mobile devices for academic searches and academic purposes.

Comparing Atiso and Boye's study, it can be said that as the years went by, most graduate students decided to use the Internet via mobile devices since $40 \%$ of the graduate students used it daily while $17.2 \%$ of them used it weekly. Testing these findings on the TAM for wireless Internet, Lu et al. (2003) attested that the perceived usefulness and ease of use are thus user's beliefs on information technology and therefore determine user's attitude towards technology which in turn suggest the acceptance (intention to use technology). The findings also agree with Revere et al., (2007) assertions that there is the need for rapid access to information to support critical decisions of graduate students' academic works which cannot be disputed. However, development of such systems requires an understanding of the actual information needs of students. 


\section{Problems of Network Providers}

The findings of the study show that the graduate students, started to discover new ways of searching for information through the Internet via mobile devices but found it difficult in accessing information because they were slow in transmitting data. Today the world is changing due to the growth of many Internet network services. After struggling with illegal file sharing during the past ten years, it would not be wrong to say that once again we are on the edge of a digital revolution. While there are many different companies offering the streaming service, which are based on different business models, some are shining in the crowd. It is the responsibility of the Mobile Services Providers to undertake regular researches to determine the challenges their users go through in patronizing their services. This will help ensure that all the challenges mentioned by the respondents are addressed to enable the users to acquire the best services needed.

\section{Challenges in Using the Mobile Devices for Internet Access}

One of the objectives of the study was to find out the challenges faced by the graduate students when using mobile devices to access the Internet. From Table 4.7 and 4.13, it was found out that most of the graduate students found low phone capabilities and screen size, memory capacity and slow transmission speed as the main challenges they faced when accessing the Internet via mobile devices. These challenges associated with the use of the Internet via mobile devices could be the reason why some students do not want to use the Internet via mobile devices. This is because like TAM for wireless Internet indicated, they might have developed bad attitudes which were influenced by the perceived challenges.

Similarly Mbambo-Thata (2010) asserts graduate students face limitations such as small screen-size, limited memory capacity and slow connectivity in accessing Internet via mobile devices. However, the findings of OkelloObura (2010) run contrary to the findings of Mbambo-Thata (2010) and Boye (2007) stating that slow Internet connectivity, unsatisfactory networked computers, lack of access to printers in libraries at low cost, how to use advanced search of databases, distinction between subject gateways and search engines, non-awareness of eresources available and the fact that lecturers did not care about students using e-resources in their coursework assignments were some of the challenges in the use of computers to access the Internet for e-resources. Also, the slow data transmission coupled with limited Internet services available to graduate students hinder the use of mobile devices for accessing Internet.

\section{Conclusions}

This study examined the use of the Internet via mobile devices among graduate students of the University of Ghana, Legon, based on TAM for wireless Internet in order to explain the perceived usefulness, perceived ease of use, and attitude and technology adoption within this conceptual frame-work.

The study's conclusion is that the TAM for wireless Internet should be applied to all graduate students' programmes because the use of the Internet via mobile devices has a unique role to perform in the UG educational system and should therefore be adopted as tools for learning. It was also concluded that the mobile service providers must provide better services to encourage more students to use mobile devices to access the Internet for academic pursuits or to search for information to supplement lecture notes. The study also realized that almost all the graduate students used one type of mobile device and were aware that they could be used to access the Internet for several purposes.

The study finally concluded that Network Service Providers must improve upon service delivery. For instance, if the network providers could improve on their transmission speed, memory capacity of their infrastructures and reduce cost of service etc, students would develop good attitudes and finally adopt their services. The use of mobile devices for accessing the Internet by the graduate students of the University of Ghana needs to be considered.

\section{Recommendations}

Finally, in pursuance of the research objectives, the following recommendations were made based on the findings of the study.

\section{Enhanced Transmission Speed}

One main reason why students will opt for the Internet to access information rather than going to the library is the faster transmission rate that comes with the Internet. The Internet is seen as a faster source from which information could be sought by students for their academic works. There is therefore the need for all the service providers to expand their broadband to accept more data transfer at the most fastest speed. Network providers should therefore endeavour to ensure that there is constant and faster internet transmission speed. This will help students to develop a positive perception and finally adopt their services

\section{Subsidized Cost of Internet Access}

Access to information is one of the fundamental rights of every Ghanaian including the graduate student as 
postulated in the 1992 Constitution. As a result, no person should be denied information because of his/her economic status. Internet Service Providers should provide services at lesser or no cost to enable students have easy access to academic information. This could be done by creating a platform on their websites or any other appropriate medium where students could subscribe to services specifically aimed at them.

\section{Constant Upgrading of Internet Infrastructure by the Service Providers}

A major challenge of Internet to Network Service Providers is the use of obsolete infrastructure. There is constant invention of IT infrastructure which renders the current ones obsolete within the shortest possible time. Since this comes at a cost, most Service Providers fail to upgrade their systems which also go a long way to affect their services. Service Providers should therefore as a matter of policy ensure that they are abreast of the current innovations in the industry so as to offer the best to their customers. If this is done, it will help customers (in this case the graduate students) to develop a positive attitude towards their services and finally adopt them as alluded to by TAM for wireless Internet.

\section{Provision of Variety of Products and Services}

Most times, people are satisfied when there are variety of products and services for them to choose from. The various Service Providers should make available to customers variety of services and products. For instance, Service Providers like MTN and Vodafone have a product like blackberry phones which support a lot of services like downloading and quicker surfing of the Internet. When this is done, students or the customers will have access to products they like and not just what is available.

\section{Partnership Between Network Providers and Manufacturers of Mobile Devices}

Producing goods and services that meet the requirements of customers is one of the main aims of production companies. In their efforts to provide services that best serve their customers, the various Internet Service Providers could enter into partnership agreements with the manufacturers of these mobile devices so that they provide products that best serve the interest of their customers. In this case, the Service Providers could state the size of the memory of the mobile devices they want for their users and even customize them to suit the kind of services they will provide.

\section{Use of Mobile Devices in Teaching and Learning at the University of Ghana}

Teaching and learning through the use of mobile devices have proved to be effective as students can submit assignments, access the library, etc even when they are not on the premises of the university. It is therefore recommended that UG authorities should consider the introduction of the use of the Internet via mobile devices in teaching and learning at all levels of the University for effective and easy access to information anywhere at any time.

Acknowledgements: Mrs. Gloria Mensah, Mrs. Rose Adjei, Joyce Arthur (Mrs), Bremini Comfort (Mrs), Veronica Kissiwaa (Miss) and Diana Adutwumwaa (Miss)

\section{References}

Abbasi, M. S., Chandio, F. H., Soomro, A. F. and Shah, F. (2010) Social influence, voluntariness, experience and the Internet acceptance, Journal of Enterprise Information Management vol. 24, No. 1, 2011 pp. 30-52.

Aboelmaged, M. G. (2010) Predicting e-procurement adoption in a developing country, Industrial Management \& Data Systems Vol. 110, No. 3, pp. 392-414

Aboelmaged, M. G. (2010) Predicting e-procurement adoption in a developing country, Industrial Management \& Data Systems Vol. 110, No. 3, pp. 392-414.

Advanced Information Technology Institute (2008) Impact of Mobile Phone Evolution. Available at: http://www.aiti_kace.com.gh/dev/? q = node/584. Accessed on 12/06/11

Aina, L. O. (2002) Research in Information Science: an African Perspective, Ibadan: Stirling Horden Publishers (Nig.) Ltd., p. 35.

Akakpo, J. (2008) Rural Access: Options and Challenges for Connectivity and Energy in Ghana, Ministry of Communications Available at: www.iicd.org. Accessed on 28/02/11.

Alreck, P. L. and Settle, R. B. (1985) The Survey Research Handbook, Homewood: Irwin. p. 67.

Alzaidiyeen, N. J., Abdullah, A. G. K., Al-Shabatat, A. M. and Seedee, R. (2011) The information aged: Examination of University Students' attitudes toward Personal Digital Assistants (PDAs) usage in terms of gender, age and school variables, The Turkish online Journal of Educational Technology Vol. 10, Issue 3, pp. 287-295.

Armah, A. L. (2010) Use of Internet Services in Ghanaian University Libraries. Available at: http://findarticles.com/p/articles/mi_7002/is_1_19/ai_n32146509/. Accessed on 12/06/11.

Asif, M. and Krogstie, J. (2011) Mobile student information system, Campus Wide Information Systems Vol. 28 
No. 1, pp. 5-15.

Asif, M. and Krogstie, J. (2011) Mobile student information system, Campus Wide Information Systems Vol. 28, No. 1, pp. 5-15.

Atiso, K.E. (2002) The Internet as a source of information for academic work. (Unpublished M. A. dissertation presented to the Department of Information Studies, University of Ghana, Legon)

Banda, L. S. (2011) What are the main determinants for the attitude to use mobile phone application in Suriname. (Unpublished MBA Thesis presented to the Maastricht School of Management and the FHR Institute for Social Studies, Maastricht School of Management, Maastricht)

Boye, L. J. (2007) Use of mobile phones by Graduate students in accessing Information for research at the University of Ghana, Legon. Unpublished MA Dissertation presented to the Department of Information Studies. Legon: University of Ghana, pp. 27-28, 74.

Bruner, G. C. and Kumar, A. (2003) Explaining consumer acceptance of handheld Internet devices, Journal of Business Research Vol. 58, pp. 553-558.

Bruner, G. C. and Kumar, A. (2003) Explaining consumer acceptance of handheld Internet devices, Journal of Business Research Vol. 58, pp. 553-558.

Bulmer, M. and Warwick, D. P. (1993) Social Research in Developing Countries: Survey and Censuses in the Third World, London: ULC Press.

Burkirwa, J. (2007) The Changing research practices and their demands on academic libraries in Africa: A researcher's point of view. Available at: www.ifla.org/iv/ifla73/. Accessed on 10/06/2011.

Busha, C. H. and Harter, S. P. (1986) Research Methods in Librarianship: Techniques and Interpretation, London: Academic Press p. 41

Chae, M. and Kim, J. (2003) What's so different about the mobile Internet? Communications of the ACM Vol.46, No.12, pp. 240-247.

Cummings, J., Merrill, A. and Borrelli, S. (2010) The use of handheld mobile devices: their impact and implications for library services, Library Hi Tech Vol. 28, No. 1, pp. 22-40.

Cummings, J., Merrill, A. and Borrelli, S. (2010) The use of handheld mobile devices: their impact and implications for library services, Library Hi Tech Vol. 28, No. 1, pp. 22-40.

Dornan, A. (2001) The Essential Guide To Wireless Communications Applications: From Cellular Systems To WAP And M-Commerce. Upper Saddle River, NJ: Prentice Hall, pp. 20-21.

Eke, H. N. (2010) The perspective of e-learning and libraries in Africa: Challenges and opportunities, Library Review, Vol. 59, No. 4, pp. 274-290.

Fraenkel, J. R. and Wallen, N. E. (2000) How to design and evaluate research in education, $4^{\text {th }}$ ed., New York: McGraw-Hill, Inc. pp. 104, 438-440.

Frempong, G. (2009) Mobile telephone opportunities: the case of micro- and small enterprises in Ghana, International Development Research Center Vol. 11, No. 2, pp. 79-94.

Gamos, S. B. (2009) Mobile Government in Africa. Available at: http://unpan1.un.org/intradoc/groups/public/documents/un/unpan033527.pdf. Accessed on 24/3/2011.

Goldman, C. (2000) Anywhere, anytime, any device? Wireless Review, Vol.1, No.2, pp. 1-2.

Kenyon, P.B and Perkins, T. (2000) China: Data in the air, The McKinsey Quarterly, No. 4, pp. 15-18.

Khan, S. (2006) Local Government and Participatory Rural Development: The case study of District Government in North West Pakistan. (PhD thesis, Gomal University, Dera Ismail Khan). Retrieved December 18, 2010 from http://prr.hec.gov.pk/Chapters/742-0.pdf.

Koul, L. (2001) Methodology of Educational Research. New Delhi: Wikas Publication House PWT Ltd. p. 22.

Krejcie, R.V. and Morgan, D.W. (1970) Determining sample size for research activity, Information and Psychological Measurement, Vol. 30, No. 3, pp. 607-610. Available at: http://www.usd.edu/ mbaron/edad810/Krejcie.pdf. Accessed on 10/11/2010.

Kwapong, O. A. T. F. (2009) Comparing knowledge and usage of ICT among male and female Distance Learners of endowed and deprived area in a developing country in Africa, Journal of Information Technology Education Vol. 8, pp. 1-17.

Langville, A. N. and Meyer, C. D. (2006) Google's PageRank and Beyond. Available at: http:// press.princeton.edu/chapters/s8216.pdf. Accessed on 8/03/11.

Liu, Y. and Li, H. (2010) Mobile Internet diffusion in China: an empirical study, Industrial Management \& Data Systems Vol. 110, No.3, pp. 309-324.

Longe, O., Ngwa, O., Wada, F. and Mbarika, V. (2009) Criminal uses of Information and Communication Technologies in Sub-Saharan Africa: Trends, Concerns and Perspectives, Journal of Information Technology Impact Vol. 9, No. 3, pp. 155 -172.

Lu, J., Yu, C., Liu, C. and Yao, J. E. (2003) Technology acceptance model for wireless Internet: Internet Research: Electronic Network Applications and Policy Vol.13, No.3, pp. 206-222.

Lu, J., Yu, C., Liu, C. and Yao, J. E. (2003) Technology acceptance model for wireless Internet: Internet Research: 
Electronic Network Applications and Policy Vol.13, No.3, pp. 206-222.

Lu, J., Yu, C., Liu, C. and Yao, J. E. (2003) Technology acceptance model for wireless Internet: Internet Research: Electronic Network Applications and Policy, Vol.13, No.3, pp. 206-222.

Lu, J., Yu, C., Liu, C. and Yao, J. E. (2003) Technology acceptance model for wireless Internet: Internet Research: Electronic Network Applications and Policy Vol.13, No.3, pp. 206-222.

Mafe, C. R., Blas, S. S. and Tavera-Mesias, J. F. (2010) A comparative study of mobile messaging services acceptance to participate in television programmes, Journal of Service Management Vol. 2, No.1, pp. 69-102.

Mbambo-Thata, B. (2010) Assessing the impact of new technology on internal operations: with special reference to the introduction of mobile phone services at UNISA library, Library Management Vol. 31, No. 6, pp. 466475.

Mbambo-Thata, B. (2010) Assessing the impact of new technology on internal operations: with special reference to the introduction of mobile phone services at UNISA library, Library Management, Vol. 31, No. 6, pp. 466475.

Neuman, L. W. (2007) Social Research Methods: Qualitative and Quantitative Approaches, $5^{\text {th }}$ ed., Boston: Pearson Education, Inc. pp. 142, 167.

Nwana, O. C. (1982) Teacher participation in health appraisal. West African Journal of Education 23 (2\&3), 139152

Okello-Obura, C. (2010) Assessment of the problems LIS postgraduate students face in accessing e-resources in Makerere University, Collection Building Vol. 29, No. 3, pp. 98-105.

Okello-Obura, C. (2010) Assessment of the problems LIS postgraduate students face in accessing e-resources in Makerere University, Collection Building, Vol. 29, No. 3, pp. 98-105.

Oliver, T. (2005) Australian University Students' use of and attitudes towards mobile learning technologies. IADIS International Conference Mobile Learning pp. 193-197 Available at: http://www.iadis.net/dl/final_uploads/2005 06coo4.pdf. Accessed on 7/01/11.

Oliver, T. (2005) Australian University Students' use of and attitudes towards mobile learning technologies. IADIS International Conference Mobile Learning pp. 193-197 Available at: http://www.iadis.net/dl/final_uploads/2005 06coo4.pdf. Accessed on 7/01/11.

Pitt, L. F., Parent, M., Junglas, I., Chan, A. and Spyropoulou, S. (2011) Integrating the smartphone into a sound environmental information systems strategy: principles, practices and a research agenda: Journal of Strategic Information Systems Vol. 20, pp. 27-37.

Putzer, G. J. and Park, Y. (2012) Are physicians likely to adopt emerging mobile technologies? Attitudes and innovation factors affecting smartphone use in the southeastern United States. Available at: http://perspectives.ahima.org/index.php?option=com content\&view=article\&id=241\&Itemid=56. Accessed on $12 / 5 / 2012$.

Revere, D., Turner, A.M., Madhavan, A., Rambo, N., Bugni, P.F., Kimball, A.M., and Fuller, S.S. (2007) Understanding the information needs of public health practitioners: A literature review to inform design of an interactive digital knowledge management system, Journal of Biomedical Informatics, Vol. 40, pp. 410 421.

Riquelme, H. E. and Rios, R. E. (2010) The moderating effect of gender in the adoption of mobile banking, International Journal of Bank Marketing Vol. 28, No. 5, pp. 328-341.

Riquelme, H. E. and Rios, R. E. (2010) The moderating effect of gender in the adoption of mobile banking, International Journal of Bank Marketing Vol. 28, No. 5, pp. 328-341.

Sarantakos, S. (1993) Social Research, Hampshire: Palgrave, pp. 6, 151.

School of Research and Graduate Studies (2009) University of Ghana handbook for graduate studies, Legon: University of Ghana, Vol. 2, pp. 1-178.

School of Research and Graduate Studies (2010) University of Ghana handbook for graduate studies, Legon: University of Ghana, Vol. 1, p. 9.

School of Research and Graduate Studies (2011) Graduate Admissions for the 2011-2012 Academic Year. Available at: http://srgs.ug.edu.gh/announcement.php?id=31. Accessed on 30/4/12.

Stark, R. and Roberts, L. (1996) Contemporary Social Research Methods, Bellevue: MicroCase Corporation. pp. $150-152$.

Tagoe, M. (2009) A handbook for writing research proposals, Accra: Ghana University Press, p. 42.

University of Ghana (2010) Basic Statistics, Legon: University of Ghana, p. 11.

Yerushalmy, M. (2004) The Institute for Alternative in Education, University of Haifa. Available at: http://www.aace.org . Accessed on 10/06/201 